\title{
Modeling of Osmotic Dehydration Kinetics of Banana Slices using Artificial Neural Network
}

\author{
S.L.Pandharipande \\ Associate Professor \\ Department of Chemical \\ Engineering, LIT, RTMNU, \\ Nagpur, India
}

\author{
Saurav Paul \\ B.Tech, \\ Department of Chemical \\ Engineering, LIT, RTMNU, \\ Nagpur, India
}

\author{
Ankit Singh \\ M.Tech IV semester \\ Department of Chemical \\ Engineering, LIT, RTMNU, \\ Nagpur, India
}

\begin{abstract}
Osmotic dehydration of fruits is one of the oldest forms of food preservation techniques known to man. Osmotic dehydration is affected by several factors such as osmotic agent, solute concentration, temperature, time, size, and shape and tissue compactness of the material, agitation and solution/sample ratio. The application of osmotic dehydration includes musk melon, banana, papaya, mango, onion slices cucumber and carrot. Artificial Neural Network is a black box tool for the modeling of processes involving multivariable non linear relationships. The present work is aimed at the study of effect of time, temperature and concentration of osmotic solution on the weight reduction for the process of osmotic dehydration of banana slices. The experimental data of osmotic dehydration kinetics generated have been used to develop a mathematical model using regression analysis. Artificial neural network models having different topologies are developed. The comparison between ANN models is carried out based on the relative error values of all the output data points. ANN model 1 is observed to be superior than model 2. The comparison is also carried out between the output values obtained by ANN model 1 and the mathematical model using regression analysis.
\end{abstract}

\section{Keywords}

artificial neural network, osmotic dehydration, modeling, banana slices.

\section{INTRODUCTION}

Dehydration of the fruits and vegetables is one of the oldest forms of food preservation techniques known to man. Osmotic dehydration is used for partial removal of water from materials such as fruits and vegetables by immersing in aqueous solutions of high osmotic pressure such as sugar and salts. The most commonly used osmotic agents are sucrose for fruits and sodium chloride for vegetables. Osmotic dehydration can be conducted at low temperature and is less energy intensive than convective drying or freezing. The main advantages of Osmotic Dehydration include better colour, texture and flavor retention along with minimum heat damage. Osmotic dehydration is affected by several factors such as osmotic agent, solute concentration, temperature, time, size, and shape and tissue compactness of the material, agitation and solution/sample ratio.

This paper presents the study of effect of time, temperature and concentration of osmotic solution on the weight reduction during the process of osmotic dehydration of banana and to develop mathematical model of osmotic dehydration kinetics.
Effects of osmotic dehydration on mass transfer properties as water loss, solid gain and weight reduction during osmotic dehydration have been investigated by various researchers. Jain S.K. et al ${ }^{[1]}$ observed that papaya cubes can be partially dewatered by osmotic dehydration in sugar solution. Graziella C.Antonio et al ${ }^{[2]}$ reported that the weight loss during osmotic dehydration of papaya pieces was influenced positively by the temperature, sucrose and lactic acid concentration and negatively by the sample geometry.

Kephas Nowakunda et al ${ }^{[3]}$ found that water loss, solids gain and weight loss increased with duration of treatment. Most efficient water removal occurred between 0.5 to 2 hours indicating that it may not be necessary to carry out the osmotic treatment step for longer hours. Alakali J.S et al ${ }^{[4]}$ found that rate of water loss in the plaintain chips increases as both temperature and syrup concentration increases. Sunjka P.S et al ${ }^{[5]}$ reported that in osmotic dehydration of cranberries time and concentration of osmotic agent significantly promoted the moisture removal and sugar uptake.

In the research work by Jain S.K et al ${ }^{[1]}$ effects of immersion temperature, solute concentration and osmotic duration on water loss and sugar gain were observed for ripe papaya cubes. The regression analysis was carried out to develop mathematical models for water loss and sugar gain of papaya cubes during osmotic dehydration. Mass Transfer was quantitatively investigated by Aniko Matusek et al ${ }^{[6]}$ et al during osmotic dehydration of carrot slices and layers. D.Konopacka ${ }^{[7]}$ studied the effect of different osmotic agents on the sensory perception of osmo treated dried fruits.

An Artificial Neural Network (ANN) is an information processing interdisciplinary theme that is inspired by the working principle of biological nervous system. It is composed of large number of highly interconnected processing elements (neurons) working in unison to solve specific problem as described by Anderson ${ }^{[8]}$ \& Pandharipande ${ }^{[9]}$.

The most common for chemical engineering application is Multi Layer Perception (MLP).It is basically a feed forward neural network. It has a multilayer structure consisting of input and output layers with at least one layer of processing units termed as hidden layer in between them. The nodes between the two successive layers are fully connected by means of weights. That is outputs from the input layer are fed to hidden layer units, which in turn, feed their outputs to the next hidden nodes. For the training of such a MLP error back propagation algorithm suggested by Rumelhart ${ }^{[10]}$ is popular. This is based on a nonlinear version of the Windro-Hoff rule known as Generalized Delta Rule (GDR). Various 
applications of ANN are, an approach to fault diagnosis in chemical processes as studied by Fan et $\mathrm{al}^{[11]}$, fault diagnosis in complex chemical plants as reported by Hoskins et $\mathrm{al}^{[12]}$, incipient fault diagnosis of chemical process as reported by Watanabe ${ }^{[13]}$, leak detection in liquefied gas pipeline as suggested by Belsitor ${ }^{[14]}$ and Pandharipande ${ }^{(15)}$, study for estimation of mass transfer coefficient for fast fluidized bed solids by Zamankhan ${ }^{[16]}$, modeling of distillation column by Baratti et $\mathrm{al}^{[17]}$. Pandharipande et al have studied various artificial neural network applications such as detergent formulation ${ }^{[18]}$, modeling of unsteady heat conduction in semi infinite solid ${ }^{[19]}$, prediction of mass transfer coefficient in down flow jet loop reactor ${ }^{[20]}$ and modeling of packed column ${ }^{[21]}$ and modeling of steam tables ${ }^{[22]}$, modeling of GurneyLurie \& Heisler charts ${ }^{[23]}$, and similar other ${ }^{[24,[25]}$ are also reported. Modeling of tomato drying using artificial neural networks by Kamyar $\mathrm{M}$ et al ${ }^{[26]}$ is reported recently.

\section{MATERIALS AND METHODS:}

- Experiments were performed for determining the weight reduction during osmotic dehydration of banana slices for various operating parameters.

- Conventional mathematical model using regression analysis was developed.

- Artificial Neural Network models based on the experimental results using elite-ANN ${ }^{\circledR}{ }^{(27)}$ was developed.

- Comparative study of the output of various models developed has been carried out.

Procedure: Five slices of banana $6-8 \mathrm{~mm}$ thick and $30 \mathrm{~mm}$ diameter approx each were weighed using electronic balance and dipped in to $100 \mathrm{ml}$ of $30 \%, 40 \%$ and $50 \%$ of sucrose solution. After every fifteen minutes of time interval, slices were removed, wiped off using filter papers and weighed. The procedure was repeated for $45^{\circ} \mathrm{C}$ and $65^{\circ} \mathrm{C}$. The $\%$ weight reduction was calculated for each observation.

\section{RESULTS AND DISCUSSION:}

Effect of time on \% weight reduction:

The figure number $1,2 \& 3$ show the graph plotted between $\%$ weight reduction of banana slices against time of osmosis at sucrose concentrations of $30,40 \& 50 \%$ and temperature conditions of $27,45 \& 65^{\circ} \mathrm{C}$ respectively. The weight reduction increased non-linearly with temperature. It is observed that the \% weight reduction is more in the initial period of osmosis. This may be due to osmotic driving potentials that keep on decreasing with time as the moisture keeps moving from banana sample to solution and the solid from solution to the sample. Further, progressive solid uptake from solution results in the formation of high solid subsurface layer, which interferes with the concentration gradients across the sample-solution interface and acts as a barrier against removal of water and uptake of solid.

It is observed that the water loss increases with the duration of osmosis.
Fig1: Effect of 30\% sucrose solution on \% weight reduction with time

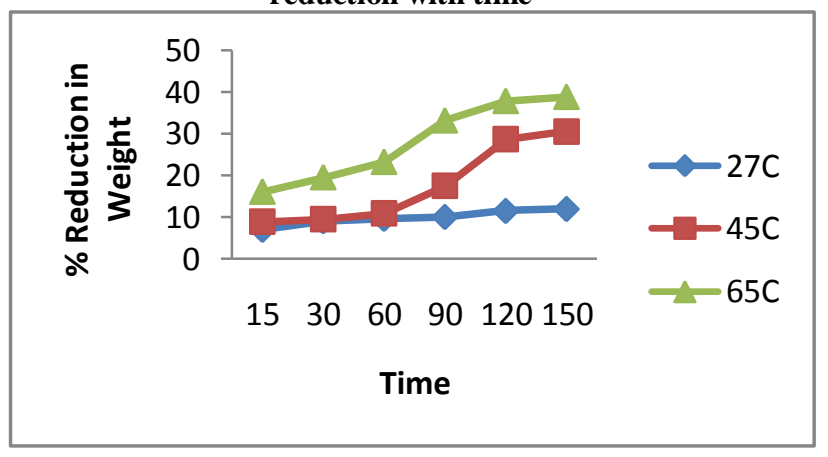

Fig2: Effect of $40 \%$ sucrose solution on $\%$ weight reduction with time

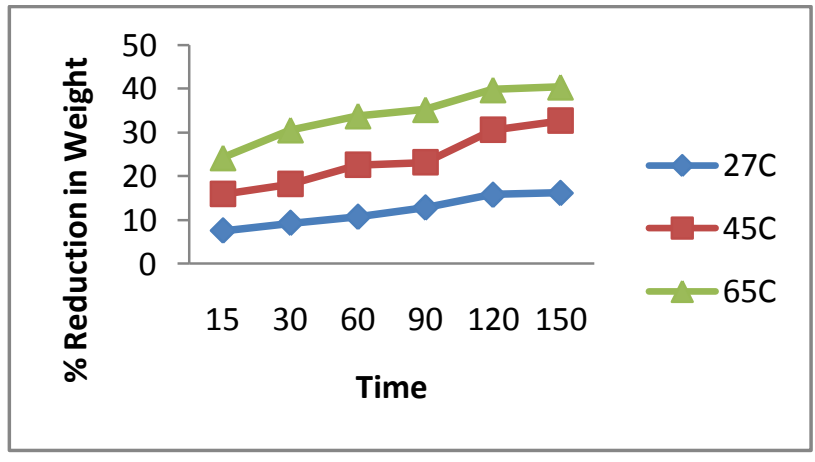

Fig 3: Effect of 50\% sucrose solution on \% weight reduction with time

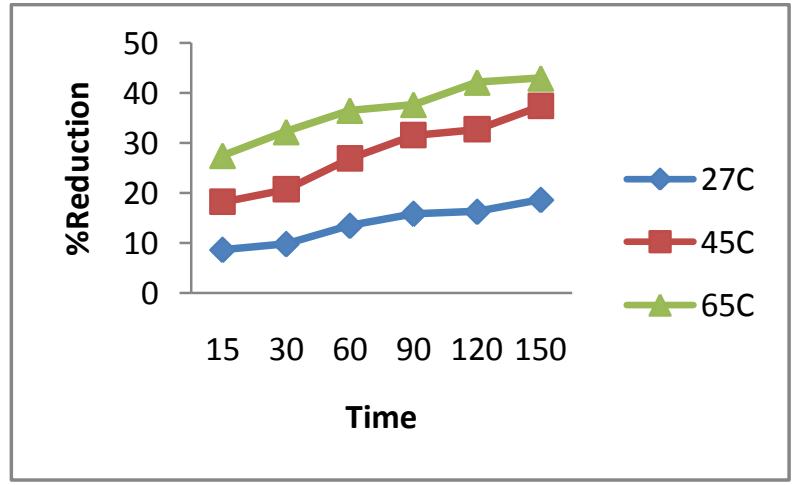

Effect of concentration of osmotic solution on $\%$ weight reduction:

The figure number $4,5 \& 6$ show the graph plotted between $\%$ weight reduction of banana slices with temperature for various concentrations of sucrose solution. It is seen that $\%$ weight reduction varies linearly with temperature of the sucrose solution. This may be due to changes in semi permeability of the cell membrane of the fruit, allowing more water to diffuse out in a shorter period.

Weight reduction also increases with increase in sucrose solution concentration at a constant temperature of sucrose solution. This may be due to increased osmotic pressure in the sucrose solution at higher concentrations, which increases the driving force. Thus it can be said that weight reduction can be increased either by increasing the sugar syrup temperature or by increasing concentration of solution. 
Fig 4: Effect of concentration of osmotic solution on weight reduction at $270 \mathrm{C}$

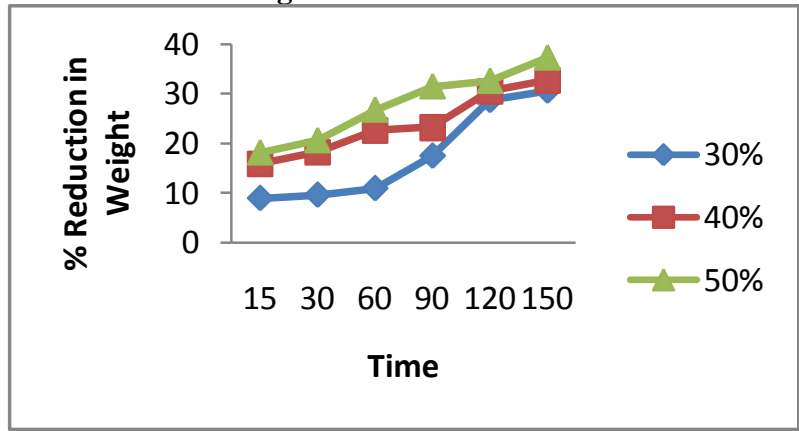

Fig 5: Effect of concentration of osmotic solution on weight reduction at $450 \mathrm{C}$

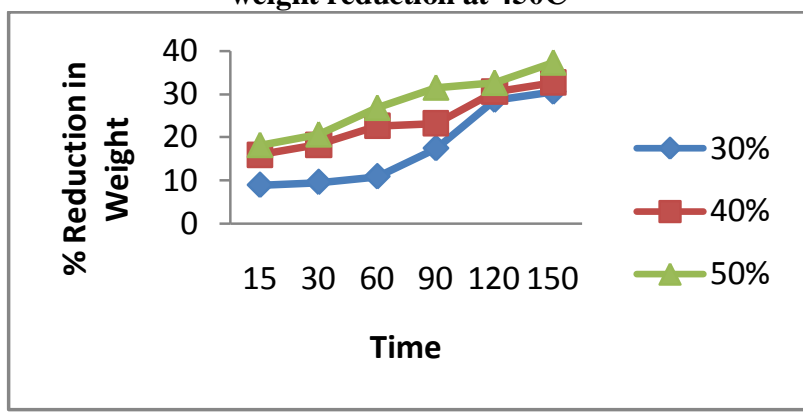

Fig 6: Effect of concentration of osmotic solution on weight reduction at $65^{\circ} \mathrm{C}$

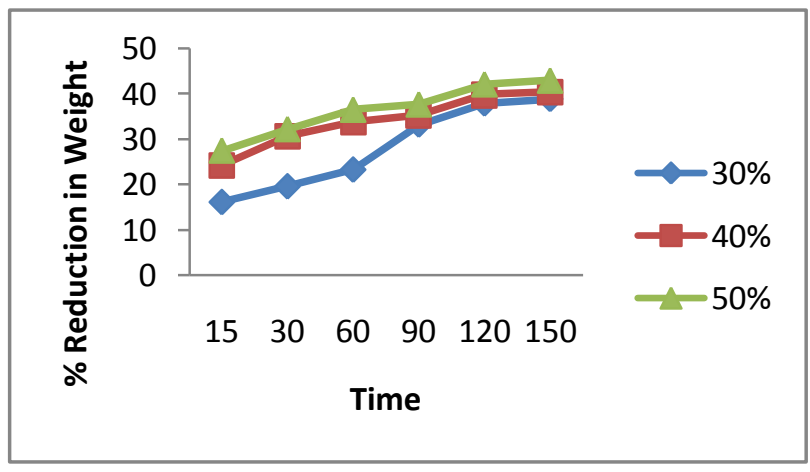

\section{Product quality:}

Visual observation of colour of sample: for room temperature condition, there was very little or no change in the colour of the samples with time. However there was gradual browning of the samples with time when osmotic dehydration was carried out at higher temperature conditions such as $45^{\circ} \mathrm{C} \&$ $65^{\circ} \mathrm{C}$

Hardness: The hardness of the samples decreased with time during osmotic dehydration for all process conditions. However the decrease in the hardness was more at higher temperature conditions. The products obtained after osmotic dehydration are much softer than the fresh ones.

\section{Regression Analysis for estimation of weight \% reduction:}

Regression analysis method is employed to develop a model based on experimental data that will correlates weight reduction ' $W R$ ' as a function of concentration of osmotic solution ' $\mathrm{C}$ ', temperature of solution ' $\mathrm{T}$ ' and time duration of osmosis ' $t$ '. The desired equation is of the form

$$
\mathrm{WR}=\mathrm{aC}^{\mathrm{b}} \mathrm{T}^{\mathrm{c}} \mathrm{t}^{\mathrm{d}}
$$

where $a, b, c$ and $d$ are constants that are determined from the experimental data as

$a=4.057 * 10^{-3}, b=0.7664, c=1.1636, d=0.3206$

The resulting equation becomes

$$
W R=4.057 * 10^{-3} C^{0.7664} T^{1.1636} t^{0.3206}
$$

A graph is plotted between the actual and estimated values of $\%$ weight reduction as shown in fig 7 . It can be seen that there is a close agreement between observed and predicted values of weight reduction.

Fig 7: Comparison of measured and predicted values of weight reduction using regression analysis

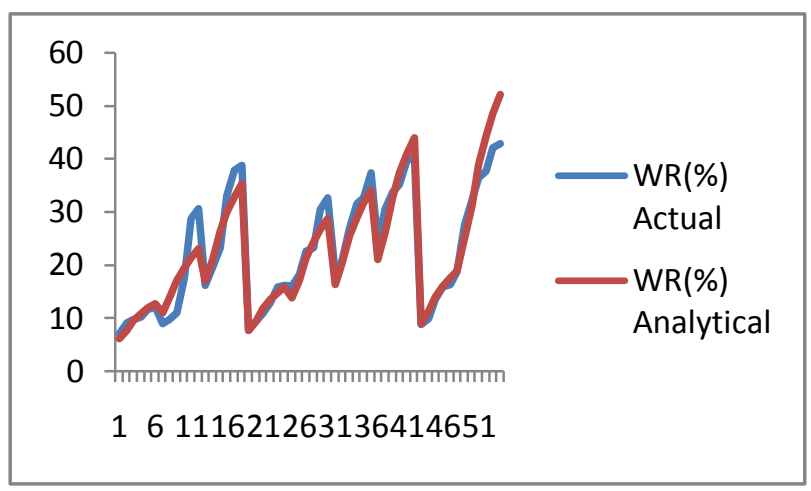

\section{Modeling using elite-ANN ${ }^{\oplus}$ :}

There are 3 input parameters namely concentration of osmotic solution (C), temperature of osmotic solution (T) and duration of osmosis (t) and \% reduction in weight (WR) as 1 output parameter. The schematic of the typical ANN architecture used in the present work is as shown in the fig:8

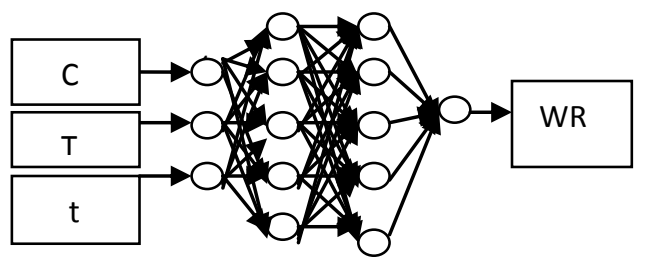

Fig 8: Typical architecture of topology of ANN models

ANN model 1 using topology 1:

The total data set is divided in to two parts. One part is called as training data set and other is test data set. The training of the ANN is done by using the training data set and its validation in estimation is judged by the test data set. The details of topology of ANN model 1 is given in table no 1 .

A graph is plotted between the measured and predicted values of output parameters for training data set as shown in fig 9. As 
can be seen from the graph there is a close agreement between the measured and predicted values indicating high accuracy of ANN model developed.

Table no 1: Details of topology of ANN models
A graph is plotted between the measured and predicted values of output parameters for training data set as shown in fig 11 . As can be seen from the graph there is a close agreement between the measured and predicted values indicating high accuracy.

\begin{tabular}{|c|c|c|c|c|c|c|c|c|}
\hline \multirow{2}{*}{$\begin{array}{c}\text { Name of } \\
\text { Model }\end{array}$} & \multicolumn{5}{|c|}{ Number of Neurons } & \multirow[b]{2}{*}{ Learning rate } & \multicolumn{2}{|c|}{ RMSE } \\
\hline & $\begin{array}{l}\text { Input } \\
\text { Parameters }\end{array}$ & $\begin{array}{l}\text { Output } \\
\text { Paramet } \\
\text { ers }\end{array}$ & $\begin{array}{c}1^{\text {st }} \\
\text { hidden } \\
\text { layer }\end{array}$ & $\begin{array}{l}2^{\text {nd }} \\
\text { hidden } \\
\text { layer }\end{array}$ & $\begin{array}{c}3^{\text {rd }} \\
\text { hidden } \\
\text { layer }\end{array}$ & & $\begin{array}{c}\text { Training data } \\
\text { set } \\
42 \text { points }\end{array}$ & $\begin{array}{c}\text { Test data } \\
\text { set } \\
12 \text { points }\end{array}$ \\
\hline ANN Model 1 & 03 & 01 & 00 & 10 & 10 & 0.5 & 0.0049 & 0.2100 \\
\hline ANN Model 2 & 03 & 01 & 00 & 05 & 05 & 0.3 & 0.0499 & 0.1276 \\
\hline
\end{tabular}

Fig 9: Comparison of measured and predicted output values of $\%$ weight reduction for training data set using ANN model 1

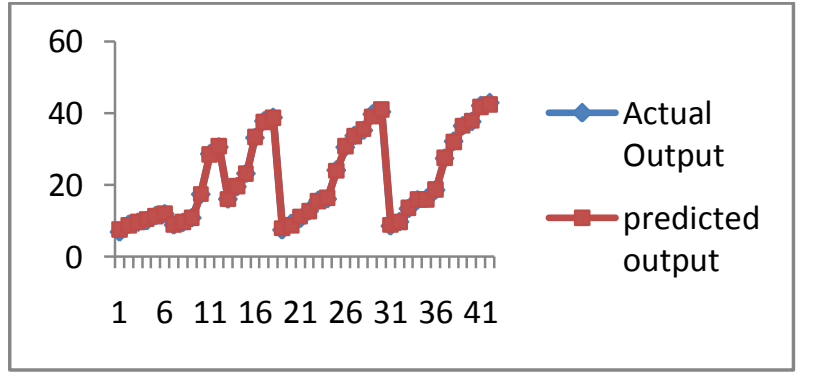

A graph is plotted between the measured and predicted values of output parameters for test data set as shown in fig 10. As can be seen from the graph there is a close agreement between the measured and predicted values indicating high accuracy of ANN model developed.

Fig 10: Comparison of measured and predicted output values of \% weight reduction for test data set using ANN model 1.

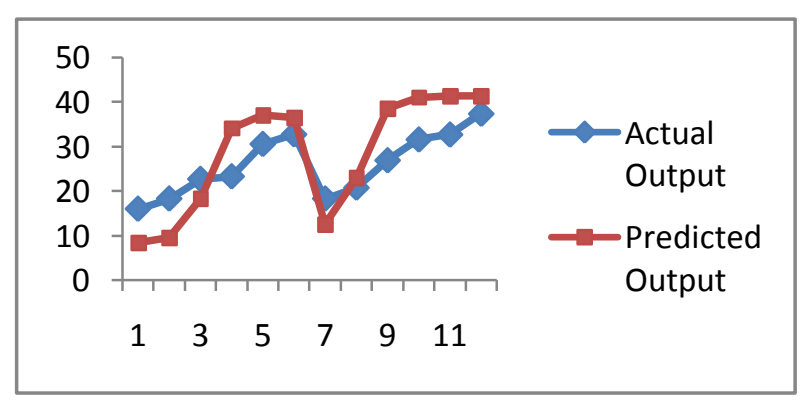

ANN model 2 using topology 2:

The details of topology of ANN model 2 is given in table no 1.
Fig 11: Comparison of measured and predicted output values of $\%$ weight reduction for training data set using ANN model 2.

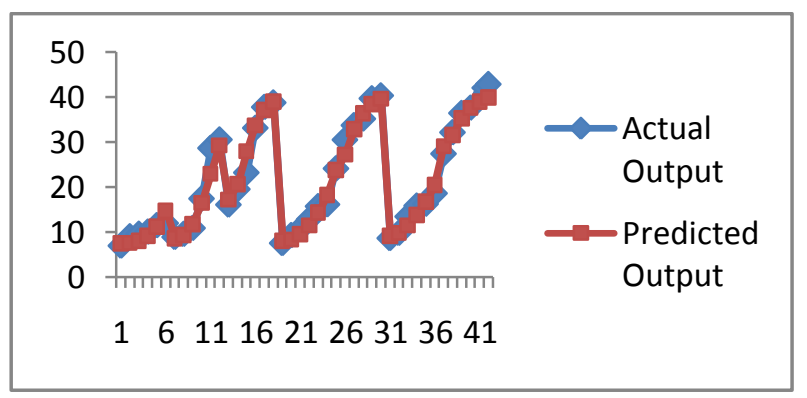

A graph is plotted between the measured and predicted values of output parameters for test data set as shown in fig 12. As can be seen from the graph there is a close agreement between the measured and predicted values indicating high accuracy.

Fig 12: Comparison of measured and predicted output values of \% weight reduction for test data set using ANN model 2.

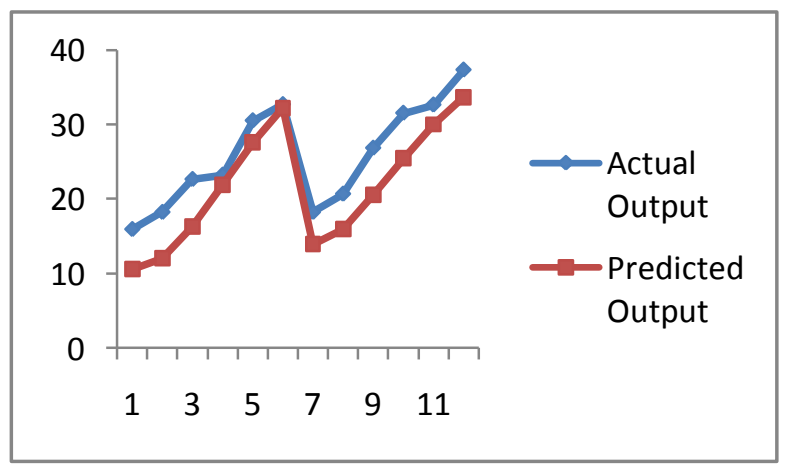

Comparison between ANN model 1 and 2:

A graph is plotted between relative errors of all the data points of output parameter \% weight reduction predicted using ANN model 1 and model 2 as shown in fig 13. From graph it is seen 
that model 1 has less relative error for most of the data points. Hence model 1 is superior than model 2 in predicting \% weight reduction.

Fig 13: Comparison of relative error of output parameter $\%$ weight reduction predicted using ANN Model 1 and Model 2.

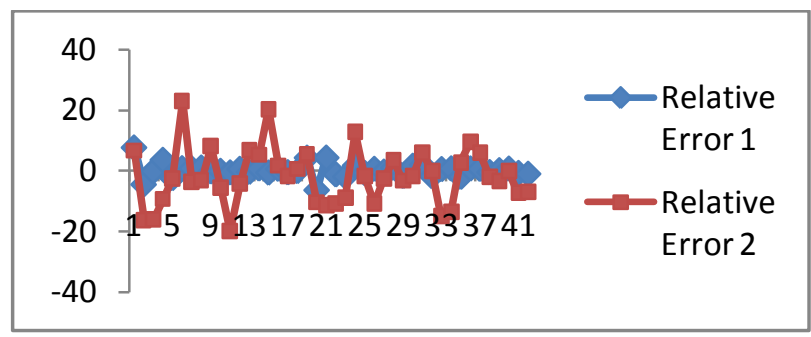

Comparison of various models developed in present work:

A comparison of the \% weight reduction predicted using models developed in the present work is carried out with the measured values. A graph is plotted between measured \& predicted values using ANN model 1 and analytical model is as shown in fig 14. As can be seen, from the graph, the \% weight reduction predicted by ANN model 1 is in close agreement with the measured values than analytical model.

Fig 14: Comparison of measured values of output parameter \% weight reduction with predicted values using analytical model and ANN model1.

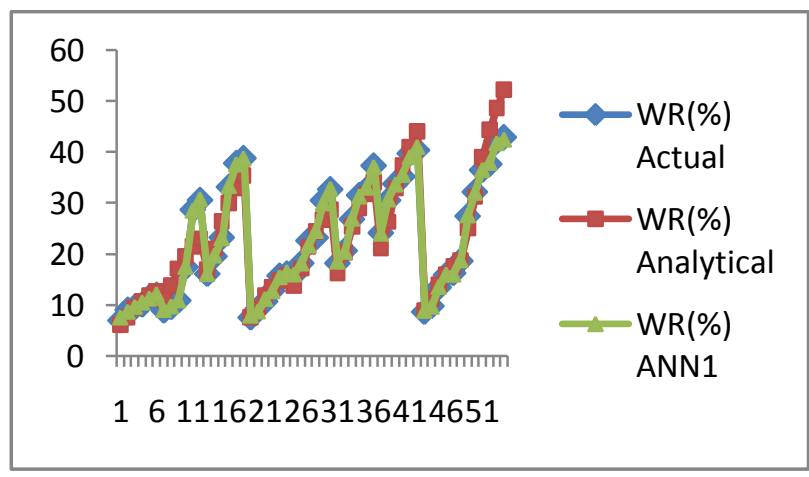

\section{CONCLUSION:}

Osmotic dehydration is gaining importance in removal of water from fruits \& other agricultural products due to its major advantage of retention of gloss, texture \& colour of dried products. The objective of the present work was to study osmotic dehydration of banana slices \& to develop ANN model for this unsteady state process. Based on the observations, results and discussion, it can be said that, banana slices can be partially dewatered by osmotic dehydration in sugar solution and \% weight reduction is from 42 to 7 depending upon the operating parameters like sugar solution concentration, solution temperature and duration of osmosis.

It can be inferred that ANN model 1 is more accurate in prediction of $\%$ weight reduction. The $\%$ relative error is within $+10 \%$ which is highly acceptable.

It can be concluded that the favored operating parameters are, sugar solution concentration around $40 \%$, temperature around $450 \mathrm{C}$ and time duration of osmosis around 100 minutes.
The present work has demonstrated the utility of ANN with high accuracy in modeling Osmotic dehydration.

\section{ACKNOWLEDGEMENT:}

Authors wish to express their sincere gratitude towards Director, Laxminarayan Institute of Technology, Nagpur for constant encouragement and the facilities provided.

\section{REFERENCES:}

[1] Jain S K, Verma R C, Murdia L K, Dashora P K, Jain H K, ADIT Journal of Engineering, 3 (2006) 72.

[2] Graziella C Antonio, Patricia M Azoubel, Denise G Alves, Anoar A El-Aouar, Fernanda E X Murr, Proceedings of the 14th International Drying Symposium, Sao Paulo, Brazil, C (2004) 1998.

[3] Kephas Nowakunda, Ana Andres, Petro Fito, Proceedings of the 14th International Drying Symposium, Sao Paulo, Brazil, C (2004) 2077.

[4] Alakali J S, Irtwange S V, and Yusuf P A, Agricultural Engineering International: the CIGR ejournal. 10 (2008) 07.

[5] Sunjka P S, Raghavan G S V, Canadian Biosystems Engineering, 46 (2004) 3.35.

[6] Aniko Matusek, Peter Meresz., Periodica Polytechnica Ser.Chem.Eng, 46 (2002) 83.

[7] D Konopacka, K Jesionkowska, R Klewicki., C Bonazzi, Journal of Horticultural Science and Biotechnology ISAFRUIT Special issue, (2009) 80.

[8] Anderson J A, An Introduction to Neural Networks (Prentice-Hall of India, Pvt Ltd, New Delhi), 1999.

[9] Pandharipande S L, An Introduction to Artificial Neural Networks (Denett Publications, Nagpur), 2008.

[10] Rumelhart D E, McClleland, Back Propagation Training Algorithm Processing, M.I.T Press, Cambridge Massachusetts, 1986.

[11] Fan J Y, Nikolau M \& White R E, AIChEJ, 39 (1993) 82.

[12] Hoskins J C, Kaliyur K M \& Himmelblau D M, AIChEJ, 37 (1991) 137.

[13] Watanabe K, Abe M, Kubota M, Himmelblau D M, AIChEJ, 35 (1989) 1803.

[14] Belsito S, Banerjee S, AIChEJ 44 (1998) 2675.

[15] Pandharipande S L \& Badhe Y P, Chem Eng World 38 (2003) 70 .

[16] Zamankhan P, Malinen P, Lepomaki H, AIChEJ, 43 (1997) 1684.

[17] Baratti R, Vacca G, \& Servida A, 74 (1995) 35-38.

[18] Pandharipande S L, Agarwal R S, Gogte B B, \& Badhe Y P, Chem Eng World 38 (2003) 78.

[19] Pandharipande S L \& Badhe Y P, Chem Eng World 38 (2003) 82.

[20] Pandharipande S L \& Badhe Y P, IChE, 45 (2003) 256.

[21] Pandharipande S L, Mandavgane S A, Indian J Chem Technol 11 (2004) 820. 
[22] Pandharipande S L, Bhaise A, Poharkar A, Chem Eng world, 39 (2004) 50

[23] Pandharipande S L, Badhe Y P, J Inst Eng, 84 (2004) 65.

[24] Pandharipande S L, Shah A M, Heena T, International Journal of Computer Applications 41 (9) (2012) 23.
[25] Pandharipande S L, Khonde R D, International Journal of Computer Applications 41 (4) (2012)

[26] Kamyar M, Maryam N, Comput. Electron. Agric, 59 (2007)78.

[27] Pandharipande S L, Badhe Y P, elite-ANN@, ROC No SW-1471 (2004) 